\title{
HORSES AND GESTALT COACHING: A PROMISING COMBINATION FOR LIFE SKILLS LEARNING
}

\author{
Māra Grēve \\ Rīga Stradiņš University, Latvia
}

\begin{abstract}
Life skills play an important role in developing adaptive behaviours that are necessary to improve one's quality of life. An individual with a broad range of life skills is more resilient than one with fewer skills. They can better withstand the challenges of constant change, successfully coping with stress and creating a fulfilling life. The aim of this research is to theoretically substantiate the possible benefits of equine-partnered gestalt coaching in life skills learning. Both Gestalt coaching and horses - specifically in context of different methods incorporated in equine assisted activities - are mentioned as they relate to the improvement of various aspects of quality of life based in life skills learning.
\end{abstract}

Keywords: gestalt coaching with horses, life skills, stress, horses, resilience.

\section{Introduction}

Life skills play an important role in developing adaptive behaviours that are necessary to improve one's quality of life. An individual with a broad range of life skills (LS) is more resilient than one with fewer skills. They can better withstand the challenges of constant change, successfully coping with stress and creating a fulfilling life. The pace of life has increased over the last few decades, and the need to handle stress in healthy ways has become more important. The lack of effective coping strategies and an inability to adapt to changes in our personal or professional lives can significantly decrease quality of life and have a negative impact on mental and physical health.

Life skills include a wide range of cognitive, social, and emotional skills. The focus of traditional educational systems might not develop all of them sufficiently well to enable us to cope effectively with life's challenges. Rapid technological progress, uncertain economic situation and changes in social norms have increased the demand for LS education. This is equally the case for adolescents who are adjusting to becoming independent individuals, for helping professionals and first responders who face high levels of stress at work, or anyone interested in leading a healthy and emotionally fulfilling life. 
The aim of this research is to theoretically substantiate the possible benefits of equine-partnered gestalt coaching in life skills learning.

Horses have played a huge role in human history, being used for labour, war, and entertainment. Nowadays in the western world, besides their role in sports and leisure, a new field of horse-human partnership is gaining in popularity. Horses are partnering with humans with the aim of offering both LS learning and healing for individuals with physical and psychosocial health problems or challenges. In this research, the main focus will be on a relatively new field in science - the psychosocial health benefits related to equine interactions, where riding is not the main or only activity. Equine-assisted learning, mostly popular for leadership training or teambuilding in corporate environments, Equine-assisted therapy, where psychotherapists combine their skills with the presence of the horse, or other Equine-assisted activities provide benefits beyond traditional therapies in the acquisition of core LS during sessions, and subsequent increases in quality of life.

Coaching as a learning experience also offers opportunities for direct or indirect LS acquisition and provides the client tools and strategies with which to approach daily challenges in more productive and successful ways. Gestalt coaching is based on the principles of Gestalt therapy, thus holding a holistic approach to problem solving and enabling the wellbeing of an individual by addressing resistances that stand in a way of necessary behaviour change. The Gestalt approach to coaching and partnering with a horse in therapeutic or learning activities both work towards the same goals. When Gestalt coaching is combined with the presence and partnership of a horse, the potential for highly effective LS learning can be amplified.

\section{Life Skills}

Life skills play a huge role in an individual's capacity to create well-being and maintain a high quality of life. The positive impact of LS training on mental health have been reported (Hajizadehanari et al., 2013; Sahu \& Gupta, 2013). LS can be defined as isolated behaviours meant to address practical aspects of life (for example, managing money, preparing a meal), or psychosocial characteristics (Hodge, Danish, \& Martin, 2013). In this research the focus will be on the latter meaning, according to this LS education definition given by World Health Organization (WHO): "Life skills education is aimed at facilitating the development of psychosocial skills that are required to deal with the demands and challenges of everyday life" (WHO, 1999; p. 1). Other terms mentioned in the literature describing methods used to increase personal competence include, but are not limited to: "social-emotional learning, 
emotional intelligence, positive psychology, resilience, and character education” (Hodge et al., 2013; 1127).

WHO describes five basic areas of LS that hold their value across different cultures: "(a) decision-making and problem-solving; (b) creative thinking and critical thinking; (c) communication and interpersonal skills; (d) self-awareness and empathy; (e) coping with emotions and coping with stress” (WHO, 1999; p.1). Increasing and strengthening competences in even a couple of those areas can improve an individual's quality of life and resilience. Resilience can be described as a process where both stress resistance and stress recovery play a part (Montpetit, Bergeman, Deboeck, Tiberio, \& Boker, 2010). Even if only one area of LS is specifically devoted to coping with stress, the other four areas also contribute to more or less of an extent.

The concept of needing LS education related to stress management is not a new one. Hays \& Eddy mentions self-confidence and self-concept as a strategy to buffer negative aspects of stressful events and informs us of the importance of four LS: values clarification, decision making, communication skills and coping skills (Hays \& Eddy, 1985). More recent information suggests including LS education into the regular school curriculum to meet the requirements of $21^{\text {st }}$ century life, and stressing the importance of equally developing social, emotional and cognitive skills. The lack of LS is associated with substance abuse and anti-social behaviour, and empathy is mentioned as a core resource for individuals to function well in society (Prajapati, Sharma, \& Sharma, 2017).

Life skills learning, especially when self-management and social skills are included, is known to improve psychological well-being for female adolescents (Bahramabadi, Manee, \& Issazadegan, 2015), is used for prevention of adolescent drug abuse (Botvin \& Griffin, 2004), and even as a tool to reduce parental stress for mothers with visually impaired children (Khooshab, Jahanbin, Ghadakpour, \& Keshavarzi, 2016).

Another important detail to consider in LS education is that learning “about” LS will not create the desired effect. The learning needs to be integrated through practical application before resulting in positive behaviour change that supports the individual's mental and emotional health. What makes LS learning successful is the chance to practice needed behaviour and experience its effects (Sahu \& Gupta, 2013). 


\section{Psychosocial Benefits from Interactions with a Horse}

The term "Equine-assisted Therapy" (EAT) can describe a wide variety activities with a horse, including riding for therapeutic reasons (Hippotherapy, Therapeutic Riding), Therapeutic Vaulting for physical capacity improvement, Therapeutic carriage driving for individuals with disabilities that do not allow them mounted exercises, Equine-assisted Activities (EAA) for mental health and personal growth, Equine-assisted Learning (EAL) or Equine-Facilitated Learning for self-awareness, confidence building and communication skills improvement, and Equine-facilitated Experiential Learning or Equine-facilitated Psychotherapy (EAP) where psychotherapists work within the range of their specialities, adding input from a horse (White-Lewis, 2019). All types of activities that involve interaction with a horse provide psychosocial benefits in some way, however in this research the focus will be on methods that do not involve riding as a main therapeutic modality.

EAL, EAA, and EAP can include various interactions with a horse mixed in a way that is unique to each specific situation, method used, and specialist who is providing the service. Those interactions can be either simply enjoying the presence of a horse, observing horse behaviour and reflecting on one's own life situations, observing horse behaviour as a result of a change in the participant's inner state, grooming the horse, working with a horse, using natural horsemanship methods, leading a horse through an obstacle course, meditation with a horse, or other. That is one reason why the effects of various methods tend to overlap, and at the same time we need to keep in mind that, when looking for a method to address specific LS learning, some might be more effective than others.

There are a couple of practical reasons why learning and healing in the presence of a horse may be preferred to other methods, for example, there is less stigma associated with Equine-assisted modalities than with traditional talk therapies in certain populations (Lee, Dabelko-Schoeny, Jedlicka, \& Burns, 2020), especially when the clients' cultural norms are less accepting of traditional western therapy (Coffin, 2019). A part of the success of EAT is the unconventional setting in which the interactions take place: the out-of-office environment, and the novelty of the process itself for many participants (Ho, Zhou, Fung, \& Kua, 2017). What is more important to consider, however, are the unique qualities horses themselves bring to LS learning that would not be available otherwise.

To start, the size of a horse and its physical capabilities relative to those of a human being evokes images, and together with interaction with a horse, can have an effect on the client's feelings, triggering fear, excitement or apathy (Notgrass \& Pettinelli, 2015). Sensitive clients, especially if they are recovering 
from emotional trauma, can relate to horses because they, as prey animals, are alert for potential dangers from predators, and their first choice would be to flee when afraid (Vidrine, Owen-Smith, \& Faulkner, 2002). When it comes to mindfulness, horses lead by example with their essence. Their natural state of being is in the present moment, fully embodied, in connection with herd members and surroundings, grazing peacefully and avoiding unnecessary expenditure of energy (Burgon, Gammage, \& Hebden, 2018). The innate sensitivity and vigilance horses have for survival reasons helps them to feel each other and in similar way - the presence of humans as well. They trust humans when we can contribute to their safety, and that means being present and congruent in our thoughts, feelings, and behaviours (Porter-Wenzlaff, 2007).

The authenticity in the behaviour horses demonstrate often encourages the client. They are not restricted by social norms human have (don't have to wear clothes, they can eat from the ground, and are allowed to leave the mess behind), and they interact in non-judgemental way (Vidrine et al., 2002). In responding to a client's behaviour using non-verbal communication, horses help the client to became aware about how the behaviour is perceived, and to identify and express feelings (Schultz, Remick-Barlow, \& Robbins, 2007).

There is also growing number of studies looking into topics how horses respond to interactions with humans. For example, they can recognize human facial expressions and respond to them both behaviourally and physiologically (Smith, Proops, Grounds, Wathanand, \& McComb, 2016); the same is true about the client's attachment style (Arrazola \& Merkies, 2020).

Considering the role of a horse in learning and healing activities is often more than that of a simple tool, there is another suggestion for how to label interventions with the involvement of the horse: "If patients gain insight and mindfulness by interacting with a sensitive horse who responds to their emotional states, a more appropriate term for equine-assisted therapy may be equine-partnered therapy” (Earles, Vernon, \& Yetz, 2015).

Interactions with a horse can benefit clients of all ages, from children to seniors. Because of the non-judgemental, non-verbal, clear communication horses offer, populations where EAT is used the most are: individuals with PTSD, people on the autism spectrum and those with ADD/ADHD, at-risk youth, prisoners for behaviour reform, individuals recovering from substance abuse, and in cases where social interaction improvement is needed (White-Lewis, 2019). The common goal in all of these situations is to evoke necessary prosocial behaviour changes that will improve overall quality of life. The effectiveness of EAT for LS learning has also been shown to enhance the professional capacity of nurses, doctors, and social workers (Jarolmen, 2018; Walsch \& Blakeney, 2013). 
The unique qualities horses bring in horse-human interactions, and the benefits clients receive, suggests that - directly or indirectly - equine-partnered interactions in both therapeutic and learning contexts, depending on the aim of the session and method used, can improve one or more of the five LS previously listed, at least to some degree. Self-awareness and empathy are the main ones addressed directly with equine-partnered therapy or learning. Those are also fundamental skills that support the successful development of all other LS areas. Communication and interpersonal skills develop naturally through interaction with another live being who is social by nature and communicates non-verbally across species. Problems coping with emotions and coping with stress are often solved by improving self-awareness and empathy and adding the horse's feedback about the congruence of the client's thoughts, feelings, and behaviours. Increasing self-awareness and empathy, improving communication and interpersonal skills, supporting emotional regulation, and building stress resilience all create a strong base for building indirect success in decision making, problem solving, creative thinking, and critical thinking. Additional specific activities can be designed to further improve creative and critical thinking depending on the client's needs.

One of the most common benefits mentioned in EAT research is an improvement in self-esteem, which, in turn, is known for lessening the effects of daily stress (Montpetit \& Tiberio, 2016), and needed for healthy relationships (Marigold, Holmes, \& Ross, 2010). An increase in self-esteem can be accompanied by increased confidence, an improvement in emotional regulation, better self-control, and a decrease in undesirable behaviours (Wilson, Buultjens, Monfries, \& Karimi, 2017).

Improved self-awareness has been reported as a result of leadership training (Kelly, 2014). This, together with improved non-verbal communication and empathy, are listed as outcomes for social workers and nurses during professional competence building with the assistance of horses (Jarolmen, 2018; Walsch \& Blakeney, 2013). Improved confidence, boundary-setting, creative thinking and problem solving, trust, partnership, and teamwork are also mentioned (Walsch \& Blakeney, 2013). Increased comfort with ambiguity, another useful trait for coping with stress, has also been reported (Murphy, Wilson, \& Greenberg, 2017).

It is hypothesized that, due to ability of a horse to invite a human to join them in a state of mindfulness, clients may experience a reduction in symptoms of anxiety (Earles et al., 2015). In combination with classical psychotherapy, not only were decreases in anxiety and depression reported, but also improved regulation of behaviour, cognitive functioning, and positive coping skills (Naste et al., 2018). Interventions involving leadership training and problem-solving skills learning can lead to improvements in communication skills the ability to 
cope with emotions and stress (Coffin, 2019). Interplay between different areas of LS is shown in another study, where improved thinking flexibility, empathy, and impulsivity control resulted in better academic performance for adolescents (Ho et al., 2017). Results show that interactions with horses are capable of decreasing levels of the stress hormone cortisol, thus decreasing the risks of developing physical and mental health problems associated with elevated levels (Pendry, Smith, \& Roeter, 2014).

The benefits of EAT as noted are extensive, partly because partnering with horses offers LS learning in the most effective way: learning by experience, involving not only cognitive engagement, but also physical and emotional (Kovács, van Dijke, \& Enders-Slegers, 2020).

Even though these findings show multiple benefits of LS learning in the presence of horses, data need to be treated carefully. Many studies lack control groups in order to fully estimate the effect of the activities (Anestis, M.D., Anestis, J.C., Zawilinski, Hopkins, \& Lilienfeld, 2014), and it is difficult to directly evaluate the effect of the horse, as activities often include many elements that contribute to the abovementioned benefits (Klontz, B.T., Bivens, Leinart, \& Klontz, T., 2007).

\section{Gestalt Coaching in Life Skills Learning}

Applying Gestalt principles in a therapeutic setting is known to enhance LS learning for children with learning disabilities and behavioural disorders, resulting in improvements in a variety of practical daily activities (independence, motor and cognitive ability, social interaction). The variety of areas influenced by gestalt therapy shows the benefits of the gestalt philosophy of working with client as a whole (Žic, Nikolić, \& Igrić, 1996).

Gestalt principles can be combined with various types of coaching, which on their own have been known to have a positive impact on wellness and quality of life through learning and implementing LS. For example, life coaching is known to improve self-awareness, self-confidence, and emotion regulation, while also helping to stop undesirable habits and create desirable behaviour change. Decreased levels of depression and anxiety are also observed (Jarosz, 2016). Co-active coaching can help to decrease levels of perceived stress, anxiety, and depression, and has resulted in increased self-awareness (Fried \& Irwin, 2016). However not all coaching interventions are successful in reducing anxiety (Jarosz, 2017). Business, leadership and executive coaching can promote psychological wellbeing and improve resilience and interpersonal relationships (Grover \& Furnham, 2016). 
Coaching as an action-based learning experience is focused on creating positive change in alignment with the client's beliefs, values, and motivations (Walk, 2009). In addition, Gestalt coaching specifically addresses resistances to change by bringing them into awareness so they can be processed and neutralised (Siminovitch \& Van Eron, 2006). As with equine-partnered activities, one of the key-elements in Gestalt coaching is present-centred awareness. This creates an opportunity to achieve new insights and practice new behaviour or actions. It is also non-judgemental, because the Gestaltist holds the client as equal, and focuses on the client's process: there is no "right" or "wrong" standard being externally imposed (Stevenson, 2005).

Life coaching based on Gestalt principles, may have similar outcomes to Gestalt therapy because, in working towards desired change, the self-awareness activated during the experiential process brings up resistances linked with client's emotions, which are addressed through experiments that allow exploration and resolution (Gillie, 2009). Gestalt theory considers learning as the process that occurs in the contact of individual with the environment, and gives guidelines for creating an optimal learning environment - one based in trust, safety, and using the client's awareness to locate and free the energy for necessary behaviour change at the appropriate time for the client (Simon, 2009).

Looking at Gestalt coaching from the LS learning perspective, again, we can see that self-awareness, coping with emotions, and developing interpersonal skills are addressed directly. Healthy decision-making and problem solving comes from the place where individual is not in conflict with oneself but has instead achieved congruence between their values and behaviours. Gestalt coaching supports that by helping the client overcome resistances and showing the benefits of values-based actions. All these outcomes increase the client's ability to cope with stress, and free emotional and cognitive resources for the improvement of creative and critical thinking. Creative thinking specifically benefits from a Gestalt approach, by providing new tools for self-exploration in an experiential setting.

\section{Conclusions}

Gestalt coaching in combination with the presence and partnership of horses holds potential for effective life skills learning. Both Gestalt coaching and partnership with horses offer optimal environment for learning, specifically: present-centred awareness and an experiential, non-judgemental, hands-on process. And both Gestalt coaching and partnership with horses work towards self-esteem building and support the behaviour changes necessary for an individual to be able to apply learned life skills in real life situations. 
All five life skills areas could be targeted directly or indirectly. Selfawareness and empathy, coping with emotions and coping with stress, and communication and interpersonal skills are the primary directly targeted areas.

As Gestalt coaching, partnership with horses, and their combination for psychosocial health improvement, represent a relatively new field of scientific study, there is a need for quantitative and qualitative research with specific life skills outcomes measured.

\section{References}

Anestis, M. D., Anestis, J. C., Zawilinski, L. L., Hopkins, T. A., Lilienfeld, S. O. (2014). Equine-Related Treatments for Mental Disorders Lack Empirical Support: A Systematic Review of Empirical Investigations. Journal of Clinical Psychology, 70(12), 1115-1132. DOI: $10.1002 /$ jclp.22113

Arrazola, A. \& Merkies, K. (2020). Effect of Human Attachment Style on Horse Behaviour and Physiology during Equine-Assisted Activities - A Pilot Study. Animals, 10(7), 1156, 1-13. doi:10.3390/ani10071156

Bahramabadi, F. G., Manee, F. M., Issazadegan, A. (2015). The effect of life skills training on psychological well-being and satisfaction among female adolescents. Journal of Research \& Health, 5(3), 347-357.

Botvin, G. J. \& Griffin, K. W. (2004). Life Skills Training: Empirical Findings and Future Directions. The Journal of Primary Prevention, 25(2), 211-232.

Burgon, H., Gammage, D., Hebden, J. (2018). Hoofbeats and heartbeats: equine-assisted therapy and learning with young people with psychosocial issues - theory and practice. Journal of Social Work Practice, 32(1), 3-16. DOI:10.1080/02650533.2017.1300878

Coffin, J. (2019). The Nguudu Barndimanmanha Project - Improving Social and Emotional Wellbeing in Aboriginal Youth Through Equine Assisted Learning. Frontiers in Public Health, 7, 278, 1-11. DOI:10.3389/fpubh.2019.00278

Earles, J. L., Vernon, L. L., Yetz, J. P. (2015). Equine-Assisted Therapy for Anxiety and Posttraumatic Stress Symptoms. Journal of Traumatic Stress, 28(2), 149-152. DOI:10.1002/jts.21990

Fried, R. R. \& Irwin, J. D. (2016). Calmly coping: A Motivational Interviewing Via CoActive Life Coaching (MI-VIA-CALC) pilot intervention for university students with perceived levels of high stress. International Journal of Evidence Based Coaching and Mentoring, 14(1), 16-33.

Gillie, M. (2009). Commentary III: Applying Gestalt Theory to Coaching. Gestalt Review, 13(3), 254-260.

Grover, S. \& Furnham, A. (2016). Coaching as a Developmental Intervention in Organisations: A Systematic Review of Its Effectiveness and the Mechanisms Underlying It. PLoS ONE 11(7): e0159137, 1-41. DOI:10.1371/journal.pone.0159137 
Hajizadehanari, K., Fard, S. M. H. S. H., Hajizadehanari, H., Yaghoubzadeh, A., Farhadian, A., Askari, M. (2013). The Effectiveness of Life Skills Education with Religious Approach to Safety, Mental Health and Self-Esteem in Elementary School Students. The European Journal of Social \& Behavioural Sciences, 5(2), 928-937.

Hayes, D. M. \& Eddy, J. M. (1985). Stress management education: A life skillsapproach for health promotion professionals. Wellness Perspectives, 2(4), 9-11.

Ho, N. F., Zhou, J., Fung, D. S. S., Kua, P. H. J. (2017). Equine-assisted learning in youths atrisk forschool or social failure. Cogent Education, 4(1), 1334430, 1-19.

DOI: 10.1080/2331186X.2017.1334430

Hodge, K., Danish, S., \& Martin, J. (2013). Developing a Conceptual Framework for Life Skills Interventions. The Counseling Psychologist, 41(8), 1125-1152.

DOI: $10.1177 / 0011000012462073$

Jarolmen, J. (2018). An Innovative Approach for Learning Self-Awareness and Nonverbal Communication. Horses for Healers. Reflections: Narratives of Professional Helping, 24(3), 28-37.

Jarosz, J. (2016). What is life coaching? An integrative review of the evidence-based literature. International Journal of Evidence Based Coaching and Mentoring, 14(1), 3456. Retrieved from http://ijebcm.brookes.ac.uk/documents/vol14issue1-paper-03.pdf

Jarosz, J. (2017). An integrative literature review on the impact of life coaching on courage, fear and anxiety. International Journal of Evidence Based Coaching and Mentoring, 15(2), 86-110.

Kelly, S. (2014). Horses for Courses: Exploring the Limits of Leadership Development Through Equine-Assisted Learning. Journal of Management Education, 38(2), 216-233. DOI: $10.1177 / 1052562913489027$

Khooshab, E., Jahanbin, I., Ghadakpour, S., Keshavarzi, S. (2016). Managing Parenting Stress through Life Skills Training: A Supportive Intervention for Mothers with Visually Impaired Children. IJCBNM, 4(3), 265-273.

Klontz, B. T., Bivens, A., Leinart, D., Klontz, T. (2007). The Effectiveness of EquineAssisted Experiential Therapy: Results of an Open Clinical Trial. Society and Animals, 15(3), 257-267.

Kovács, G., van Dijke, A., Enders-Slegers, M-J. (2020). Psychodynamic Based EquineAssisted Psychotherapy in Adults with Intertwined Personality Problems and Traumatization: A Systematic Review. Int. J. Environ. Res. Public Health, 17(16), 5661, 1-18. DOI: 10.3390/ijerph17165661

Lee, K., Dabelko-Schoeny, H., Jedlicka, H., Burns, T. (2020). Older Adults' Perceived Benefits of Equine-Assisted Psychotherapy: Implications for Social Work. Research on Social Work Practice, 30(4), 399-407. DOI: 10.1177/1049731519890399

Marigold, D. C., Holmes, J. G., Ross, M. (2010). Fostering relationship resilience: An intervention for low self-esteem individuals. Journal of Experimental Social Psychology 46(4), 624-630. DOI: 10.1016/j.jesp.2010.02.011

Montpetit, M. A., Bergeman, C. S., Deboeck, P. R., Tiberio, S. S., \& Boker, S. M. (2010). Resilience-as-Process: Negative Affect, Stress, and Coupled Dynamical Systems. Psychology and Aging, 25(3), 631-640. DOI: 10.1037/a0019268

Montpetit, M. A. \& Tiberio, S. S. (2016). Probing Resilience: Daily Environmental Mastery, Self-Esteem, and Stress Appraisal. The International Journal of Aging and Human Development, 83(4), 311-332. DOI: 10.1177/0091415016655162 
Murphy, L., Wilson, J., Greenberg, S. (2017). Equine-Assisted Experiential Learning in Occupational Therapy Education. Journal of Experiential Education, 40(4), 366-376. DOI: $10.1177 / 1053825917712732$

Naste, T. M., Price, M., Karol, J., Martin, L., Murphy, K., Miguel, J., Spinazzola, J. (2018). Equine Facilitated Therapy for Complex Trauma (EFT-CT). Journ Child Adol Trauma, 11(3), 289-303. DOI: 10.1007/s40653-017-0187-3

Notgrass, C. G. \& Pettinelli, J.D. (2015). Equine Assisted Psychotherapy: The Equine Assisted Growth and Learning Association's Model Overview of Equine-Based Modalities. Journal of Experiential Education, 38(2), 162-174. DOI: $10.1177 / 1053825914528472$

Pendry, P., Smith A. N., Roeter, S. M. (2014). Randomized Trial Examines Effects of Equine Facilitated Learning on Adolescents' Basal Cortisol Levels. Human-Animal Interaction Bulletin, 2(1), 80-95.

Porter-Wenzlaff, L. (2007). Finding their voice: developing emotional, cognitive, and behavioral congruence in female abuse survivors through equine facilitated therapy. Explore, 3(5), 529-534. DOI: 10.1016/j.explore.2007.07.016

Prajapati, R., Sharma, B., Sharma, D. (2017). Significance of Life Skills Education. Contemporary Issues in Education Research, 10(1), 1-6. DOI:10.19030/cier.v10i1.9875

Sahu, K. \& Gupta, D. (2013). Life skills and mental health. Indian Journal of Health and Wellbeing, 4(1), 76-79.

Schultz P. N., Remick-Barlow G., A., Robbins, L. (2007). Equine-assisted psychotherapy: a mental health promotion/intervention modality for children who have experienced intrafamily violence. Health and Social Care in the Community, 15(3), 265-271.

Siminovitch, D. E. \& Van Eron, A. M. (2006). The Pragmatics of Magic. The Work of Gestalt Coaching. OD Practitioner, 36(1), 50-55.

Simon, S. N. (2009). Applying Gestalt Theory to Coaching. Gestalt Review, 13(3), 230-240.

Smith, A. V., Proops, L., Grounds, K., Wathanand, J., McComb, K. (2016). Functionally relevant responses to human facial expressions of emotion in the domestic horse (Equus caballus). Biology Letters, 12, 20150907, 1-4. http://dx.doi.org/10.1098/rsbl.2015.0907

Stevenson, H. (2005). Gestalt Coaching. OD Practitioner, 37(4), 42-47.

Vidrine, M., Owen-Smith, P., Faulkner, P. (2002). Equine-facilitated group psychotherapy: Applications for therapeutic vaulting. Issues in Mental Health Nursing, 23(6), 587-603. DOI: $10.1080 / 01612840290052730$.

Walk, M. A., (2009). Commentary II: Applying Gestalt Theory to Coaching. Gestalt Review, 13(3), 247-253.

Walsh, K. M. \& Blakeney, B. A. (2013). Nurse Presence Enhanced Through Equus. Journal of Holistic Nursing, 31(2), 121-128. DOI: 10.1177/0898010112474721

White-Lewis, S. (2019). Equine-assisted therapies using horses as healers: A concept analysis. Nursing Open, 7(1), 58-67. DOI: 10.1002/nop2.377

Wilson, K., Buultjens, M., Monfries, M., Karimi, K. (2017). Equine-Assisted Psychotherapy for adolescents experiencing depression and/or anxiety: A therapist's perspective. Clin Child Psychol Psychiatry, 22(1), 16-33. DOI: 10.1177/1359104515572379

WHO. (1999). Partners in life skills education - conclusions from a united nations interagency meeting. Retrieved from http://www.who.int/mental_health/media/en/30.pdf 
Žic, A., Nikolić, B., Igrić, L. (1996). The Influence of Integrative Gestalt Therapy on Acquisition of Daily Life Skills and Habits. 10th World Congress of International Association for the Scientific Study of Intelectual Disability, 1-12. 